\title{
Artificial 3D Culture Systems for T Cell Expansion
}

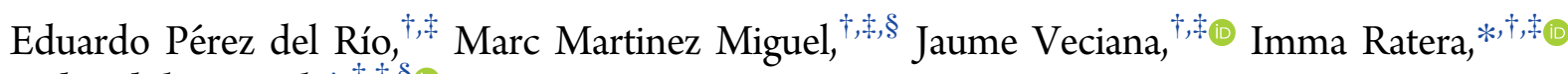 \\ and Judith Guasch $*, \dagger, \ddagger, \S(0)$
}

\begin{abstract}
${ }^{\dagger}$ Institute of Materials Science of Barcelona (ICMAB-CSIC), ${ }^{\ddagger}$ Networking Research Center on Bioengineering, Biomaterials and Nanomedicine (CIBER-BBN), and ${ }^{\S}$ Dynamic Biomaterials for Cancer Immunotherapy, Max Planck Partner Group, ICMAB-CSIC, Campus UAB, 08193 Bellaterra, Spain
\end{abstract}

\section{Supporting Information}

ABSTRACT: Adoptive cell therapy, i.e., the extraction, manipulation, and administration of ex vivo generated autologous $\mathrm{T}$ cells to patients, is an emerging alternative to regular procedures in cancer treatment. Nevertheless, these personalized treatments require laborious and expensive laboratory procedures that should be alleviated to enable their incorporation into the clinics. With the objective to improve the ex vivo expansion of large amount of specific $\mathrm{T}$ cells, we propose the use of three-dimensional (3D) structures during their activation with artificial antigen-presenting cells, thus resembling the natural environment of the secondary lymphoid organs. Thus, the activation, proliferation, and differentiation of $T$ cells have been analyzed when cultured in the presence of two 3D systems, Matrigel and a 3D polystyrene scaffold, showing an increase in cell proliferation compared to standard suspension systems.

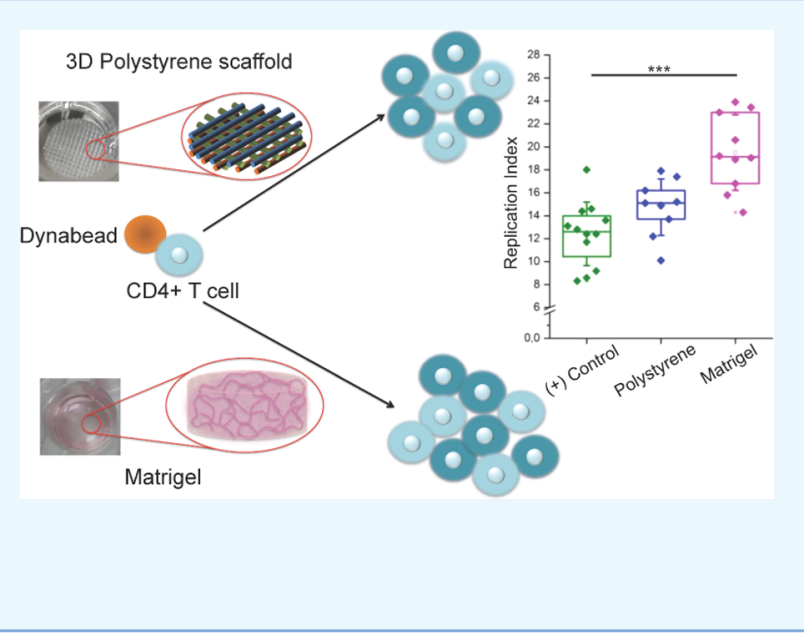

\section{INTRODUCTION}

The immune system is prepared to distinguish self from nonself entities, to be able to protect the organism from the invasion of threatening pathogens. ${ }^{1}$ Nevertheless, the self origin of cancer cells can result in immune evasion, which is considered as one of the hallmarks of cancer cells. ${ }^{2}$ Encouragingly, genetic engineering techniques are showing promising results in the production of engineered $\mathrm{T}$ cells with high specificity and efficiency toward tumor recognition and elimination. Indeed, the use of engineered $\mathrm{T}$ cells in adoptive cell therapy (ACT), resulted in partial or total remissions in patients with relapsed or refractory hematological malignancies, in clinical trials. ${ }^{3}$ However, ACT still faces challenges to overcome to accelerate its broad adoption, such as a more efficient expansion of $\mathrm{T}$ cells ex vivo of relevant phenotypes. ${ }^{3}$

Cells are able to sense and respond to chemical and mechanical properties of their environment, ${ }^{4-9}$ causing for example, Tyr phosphorylation or dephosphorylation, binding of specific lipids, or morphological changes. ${ }^{10}$ Although twodimensional (2D) cultures provide very valuable information about cellular biology, ${ }^{11-13}$ these techniques can introduce artifacts to the natural cell behavior, due to the adaptation of cells to flat surfaces, ${ }^{9}$ which differ from their three-dimensional (3D) in vivo environment. Thus, the development of suitable $3 \mathrm{D}$ environments for cell culture is highly desired, which not only would benefit cell culture techniques, but also tissue engineering, which aims at regenerating tissues or creating study models through cell-material interactions. $\mathrm{T}$ cell activation occurs in the secondary lymphoid organs after the interaction of antigen-presenting cells with $\mathrm{T}$ cells. These organs have a highly complex and densely packed structure with specific mechanical and chemical characteristics ${ }^{14}$ that allow cellular densities that are 3 orders of magnitude higher than standard cell cultures. Among the various technologies available for scaffold-based 3D cell culture, which would allow an immediate benefit given their potentially fast and low-cost transfer to the clinics, hydrogels stand as a popular option due to their biocompatibility, stiffness, porosity, and ability to be functionalized to mimic the extracellular matrix (ECM). ${ }^{9}$ Matrigel (Corning) is a well-defined gelatinous protein mixture extract prepared from the Engelbreth-Holm-Swarm mouse sarcoma, a tumor with an abundant ECM that resembles basement membranes. ${ }^{15}$ The major components of Matrigel are laminin, collagen IV, heparan sulfate proteoglycans, nidogen, and growth factors, which provide both structural and signal transduction functions. ${ }^{16}$ It has pores of $25-300 \mathrm{~nm}$ and a stiffness of $443 \mathrm{~Pa}^{17}$ similar to other ECM-based hydrogels, such as mixtures of collagen- 1 and laminin $(60: 40),{ }^{18}$ but softer than typical synthetic hydrogels, such as poly(ethylene glycol) dimethacrylate. ${ }^{19}$ Matrigel has been used in various 3D cell culture studies, mainly involving cancer cell types, such as mammary carcinoma, ${ }^{20}$ tongue carcinoma, ${ }^{21}$ and prostate carcinoma. ${ }^{22}$ However, to the best of our knowledge, these studies are limited to the analysis of the invasiveness and

Received: March 19, 2018

Accepted: April 24, 2018

Published: May 16, 2018 
migration capacity of the cells. These assays showed that $\mathrm{T}$ cell migration depends on matrix metalloproteinase (MMP) secretion, through the correlation of MMP inhibitors and migration blocking in a dose-dependent manner. ${ }^{23}$ Similarly, T lymphoblastoma cell migration was also shown to be dependent on MMP secretion. ${ }^{24}$ Specifically, the IL-2 secretion resulted in an increased MMP production, which enabled the activation of cells, which were then able to traverse the dense Matrigel matrix. Alternatively, polymer scaffolds are interesting for $3 \mathrm{D}$ cell cultures due to their diverse fabrication techniques available, such as emulsion polymerization, ${ }^{25}$ foaming, ${ }^{26}$ phase separation, ${ }^{27}$ electrospinning, ${ }^{28}$ or $3 \mathrm{D}$ printing. ${ }^{29}$ These techniques enable the production of scaffolds with controlled dimensions and a porous structure, important characteristics for a suitable cell culture system. Given that plasma-treated polystyrene is a ubiquitous material for standard $2 \mathrm{D}$ cell culture, it is not surprising that polystyrene scaffolds have been developed to serve as 3D cell culture systems. ${ }^{25-27}$ The 3D polystyrene scaffold (3D Biotek) consists of layers of parallel fibers with a stiffness of $\sim 3 \mathrm{GPa}$ and a diameter of $300 \mu \mathrm{m}$, arranged at $90^{\circ}$ and offset to each other. The resulting pore size of this structure is $400 \mu \mathrm{m}$. Such 3D polystyrene scaffold was tested for the amplification of lymphoma cancer cells, incubating mantle cell lymphoma cells in the presence of neighboring stroma cells achieving a remarkable proliferation efficiency. ${ }^{30}$ Thus, commercial 3D systems hold great potential for the culture of various cell types, not only as therapeutic agents, e.g., as prosthesis to be implanted to patients, but also as model systems to study physiological and pathogenic behaviors. Here, we analyzed the effect of adding a $3 \mathrm{D}$ environment to activate primary human $\mathrm{CD}^{+} \mathrm{T}$ cells, with the objective of enhancing the $\mathrm{T}$ cell expansion of relevant phenotypes in short periods of time to contribute to the improvement of ACT. For that two remarkably different biomaterials were chosen, Matrigel and a 3D polystyrene scaffold, to contemplate the broad spectrum of structural and physicochemical properties that current commercial materials can offer and assure that the effects observed are caused by the 3D environment and not by a particular characteristic of the scaffold.

\section{RESULTS AND DISCUSSION}

Primary human $\mathrm{CD}^{+} \mathrm{T}$ cells purified from peripheral blood (purity $\mathrm{CD}^{+} \mathrm{CD}^{+} \mathrm{T}$ cells $>90 \%$ ) were polyclonally activated using Dynabeads (Thermo Fisher Scientific), which are magnetic beads of $4.5 \mu \mathrm{m}$ in size coated with anti-CD3 and anti-CD28 that act as artificial antigen-presenting cells. Specifically, anti-CD3 interacts with the $\mathrm{CD} 3 \varepsilon$ chain of the $\mathrm{T}$ cell receptor (TCR)-CD3 complex, resulting in $\mathrm{T}$ cell activation, whereas anti-CD28 provides a costimulatory signal needed to avoid anergy. Three different environments were used, which consisted of a static suspension, Matrigel, and a 3D polystyrene scaffold. To evaluate $\mathrm{T}$ cell activation, the secretion of the cytokine IL- 2 was analyzed. IL- 2 is rapidly secreted by activated $\mathrm{T}$ cells and is known to support $\mathrm{T}$ cell proliferation and differentiation. ${ }^{31}$ Consequently, IL-2 is used in clinics to evaluate lymphocyte function and was used here to evaluate the performance of the 3D structures through an enzyme-linked immunosorbent assay (ELISA) 1 day after seeding (Figure 1). $\mathrm{CD}^{+} \mathrm{T}$ cells activated in suspension (positive control), i.e., without any 3D platform, showed a median value of $44.6 \mathrm{ng} /$ $\mathrm{mL}$, with most measured values falling into the range between 36.3 and $51.0 \mathrm{ng} / \mathrm{mL}$ (percentiles Q-25 and Q-75), due to the intrinsic variability of primary samples. These values are

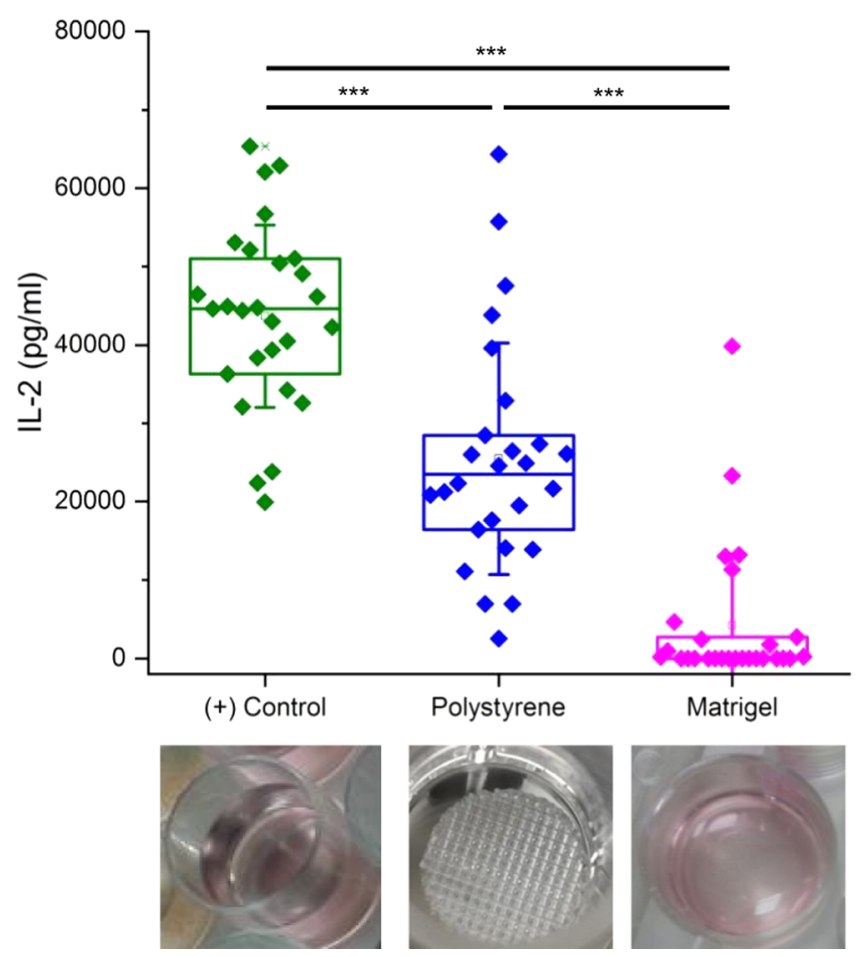

Figure 1. IL-2 secretion of $\mathrm{CD}^{+} \mathrm{T}$ cells seeded in suspension (positive control), a 3D polystyrene scaffold, and Matrigel on day 1 . All cultures were stimulated with Dynabeads for activation. The results shown were obtained from $N_{\text {donors }}=9$ and statistical significance was determined by the Mann-Whitney $U$ test $(* * * p<0.001)$.

significantly higher than those obtained in both the $3 \mathrm{D}$ polystyrene scaffolds, with a median value of $23.5 \mathrm{ng} / \mathrm{mL}$, and Matrigel, which shows negligible IL-2 results in the majority of samples. Although a diminished secretion cannot be discarded, obstructed diffusion or even retention of IL-2 to the matrices could also explain the observed results. More specifically, this phenomenon could be caused by proteoglycans in Matrigel, whereas in the $3 \mathrm{D}$ polystyrene scaffold, it would be rather unspecific. $^{32}$

In addition to the quantification of IL-2, the activation of T cells was also assessed by changes on cell morphology. Figure 2 shows that prior to activation, cells exhibit a round morphology, whereas activated $\mathrm{T}$ cells show larger sizes and elongated shapes, compatible with the ameboid migration mode, as previously reported. ${ }^{33}$ To quantify these changes, the area, perimeter, aspect ratio (AR), and circularity of cells were analyzed. The median area of resting cells was of $43.4 \mu \mathrm{m}^{2}$ (negative control), whereas cells activated in suspension and in the $3 \mathrm{D}$ polystyrene scaffold exhibited significantly larger areas with median values of 114.8 and $109.2 \mu \mathrm{m}^{2}$, respectively. The median area of activated cells using Matrigel was of $41.3 \mu \mathrm{m}^{2}$ (Figure 2E). Similarly, the perimeter and AR followed the tendencies observed for cell area (Figure 2F,G). The median value of the cell perimeter of resting cells and cells seeded in Matrigel was of $23.3 \mu \mathrm{m}$, whereas the ones in suspension and 3D polystyrene scaffold increased to 40.2 and $37.9 \mu \mathrm{m}$, respectively. The AR of resting cells was 7.3 , which grew to 11.2 for cells activated in suspension and in the $3 \mathrm{D}$ polystyrene scaffold. Cells activated on Matrigel showed an AR of 6.7. Alternatively, the circularity of cells, which is proportional to the area divided by the square of the perimeter, showed statistical changes in all activated cells in comparison to the 
(A)

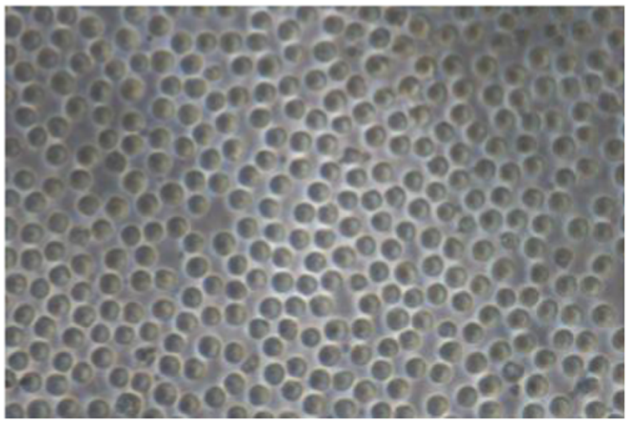

(C)

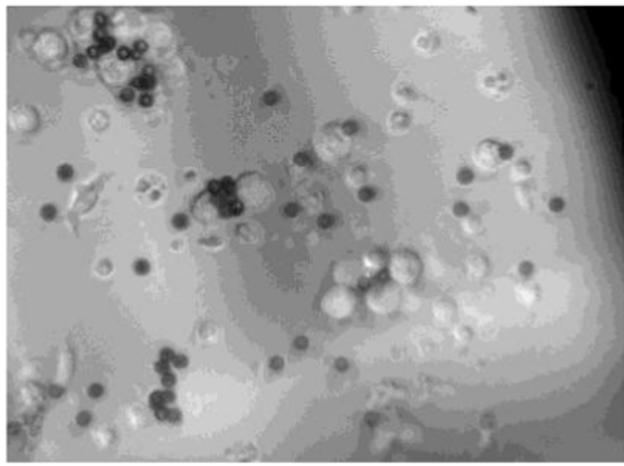

(E)

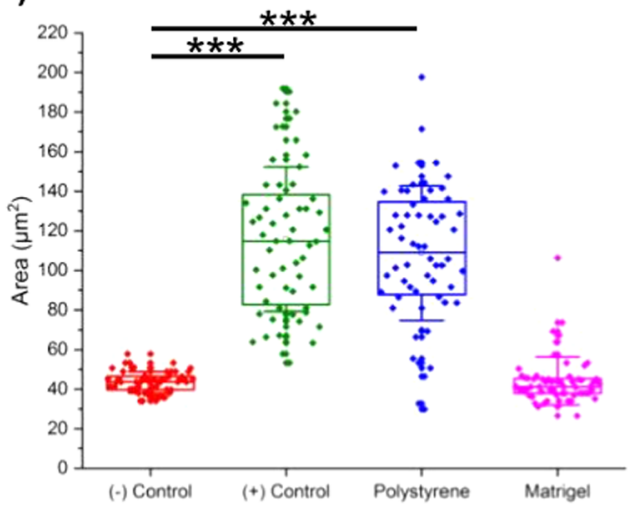

(G)

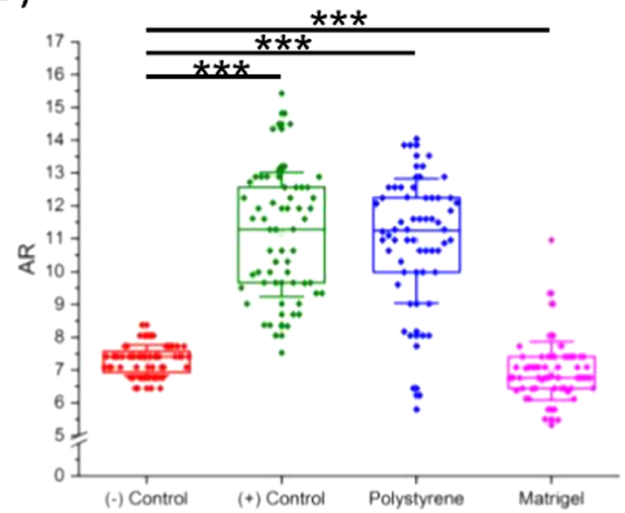

(B)

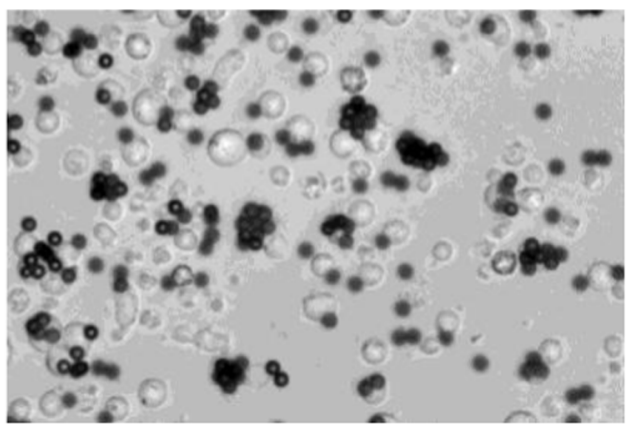

(D)

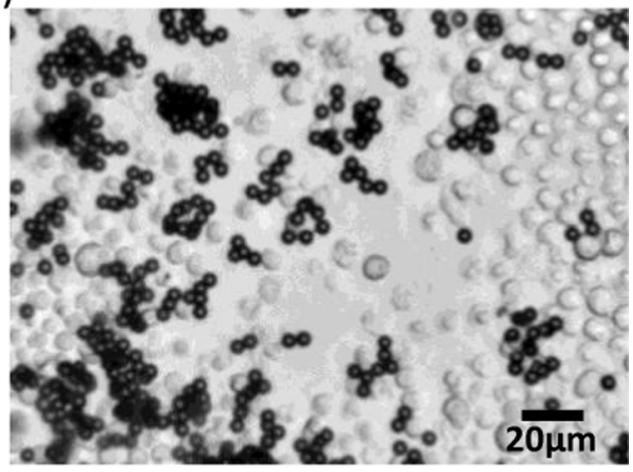

(F)

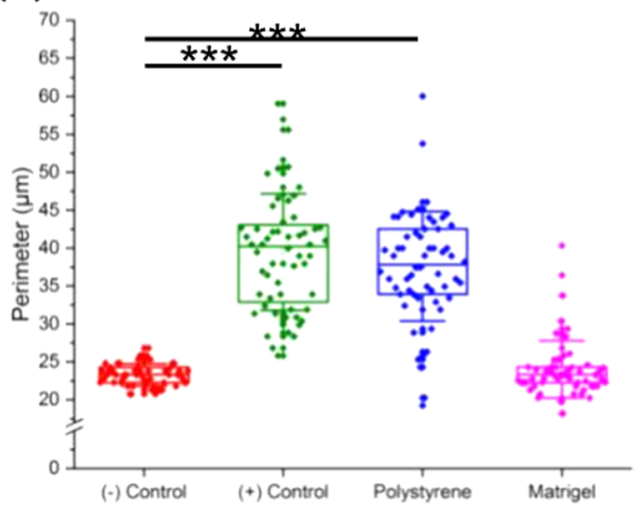

(H)

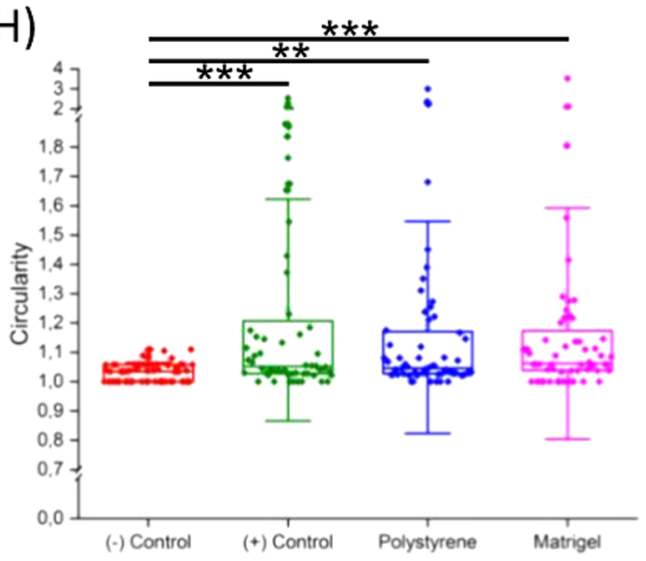

Figure 2. Representative optical images of $\mathrm{CD} 4^{+} \mathrm{T}$ cell cultures: (A) negative control (cells cultured without supply of Dynabeads), (B) positive control (in suspension), (C) in a 3D polystyrene scaffold and (D) using Matrigel cells with supply of Dynabeads (dark spheres with a bright nucleus) in a 1:1 ratio for the three last environments. Analysis of cell morphometric parameters: (E) area, (F) perimeter, (G) aspect ratio (AR), and (H) circularity were analyzed on day 2 . The results shown were obtained from $N_{\text {donors/condition }}=3$, with a minimum of $N_{\text {cells } / \text { donor }}=20$. Statistical significance was determined by the Mann-Whitney $U$ test $(* * p<0.01, * * * p<0.001)$. 
(A)

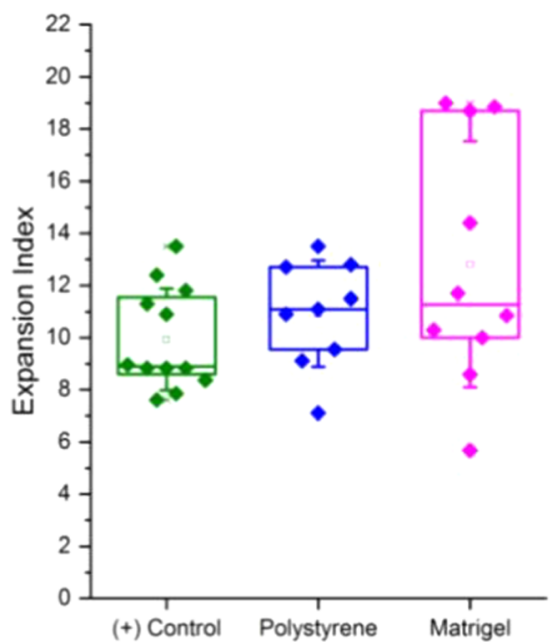

(D)

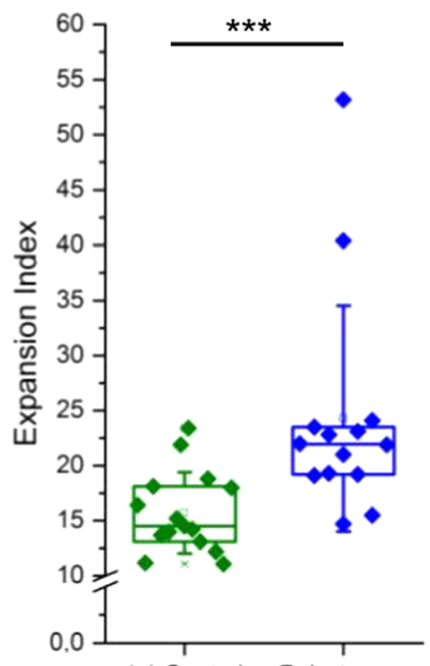

(+) Control Polystyrene
(B)

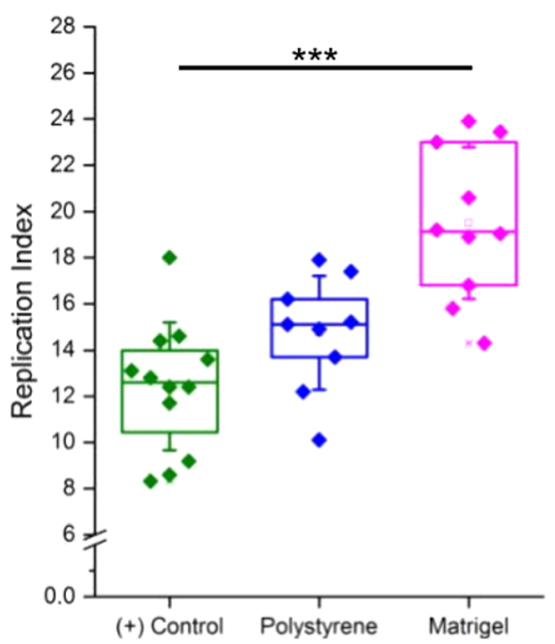

(C)

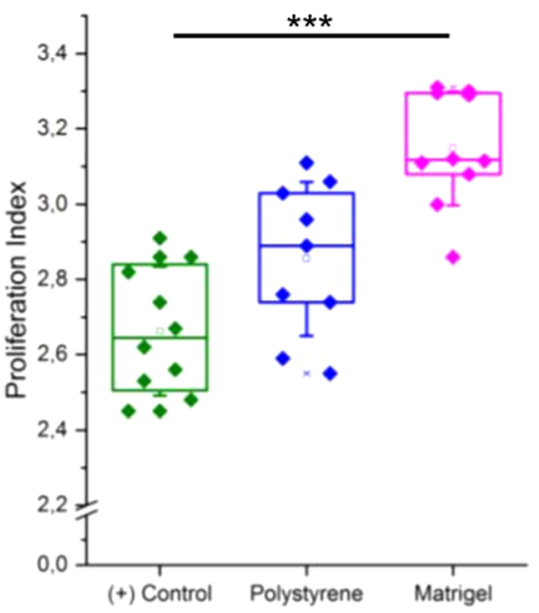

(E)

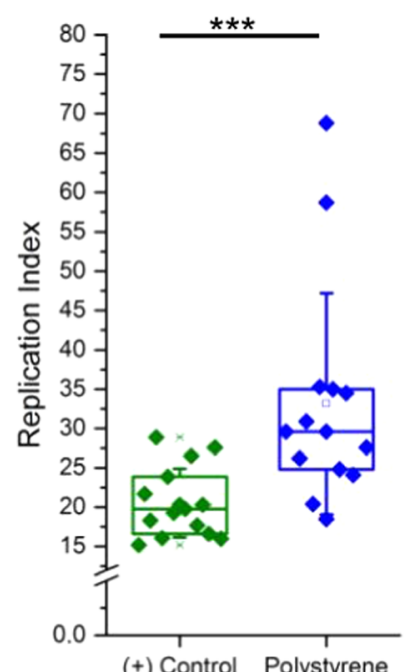

(F)

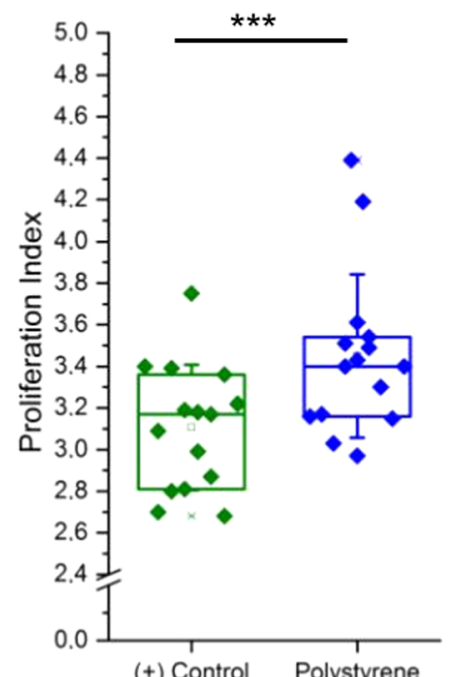

Figure 3. Proliferation analyses of $\mathrm{CD}^{+} \mathrm{T}$ cells 5 days after seeding in $3 \mathrm{D}$ polystyrene scaffolds and Matrigel $\left(N_{\text {donors }}=4\right.$, with a minimum of $N_{\text {donors/condition }}=3$ ). (A) Expansion index (fold-expansion of the whole population), (B) replication index (fold-expansion of the responding cells), and $(\mathrm{C})$ proliferation index (average number of divisions among the responding cells). Proliferation analysis of CD4 $4^{+} \mathrm{T}$ cells 6 days after seeding in 3D polystyrene scaffolds $\left(N_{\text {donors }}=5\right)$. (D) Expansion index, $(\mathrm{E})$ replication index, and (F) proliferation index. Statistical significance was determined by the Mann-Whitney $U$ test $(* * * p<0.001)$.

negative control. Although the median values were similar $(1.03$ for the negative control and 1.05 for the rest of the cases), the variability of shapes was higher in the samples with activated cells, as represented by the larger box charts (Figure $2 \mathrm{H}$ ). As expected, when $\mathrm{T}$ cells are activated, they express cell adhesion receptors that allow their spreading and adhesion, especially to available two-dimensional (2D) substrates, such as the endothelium lining, resulting in different shapes and sizes in comparison to the completely spherical shape of the resting form. ${ }^{34}$

The morphological differences observed in Matrigel compared to cells obtained in suspension or seeded in the 3D polystyrene scaffold could be explained by the dimensionality of the material. ${ }^{35-37}$ The $\mathrm{T}$ cells seeded in suspension but analyzed under the optical microscope, tend to be those attached to the bottom of the culture well, thus responding to a flat substrate. Similarly, the large pore size of the $3 \mathrm{D}$ polystyrene scaffold, might also promote some $2 \mathrm{D}$ interactions. In contrast, Matrigel offers a truly 3D structure, which promotes spherical shapes with blebs as protrusions characteristic of the ameboid migration. ${ }^{34}$ Although such migration mode usually results in low adhesion, the dense mesh of Matrigel consisting of ECM proteins and growth factors, could also play a role through modifications on the phenotype obtained after proliferation.

In the next step, $\mathrm{T}$ cell proliferation was assessed through the expansion, replication, and proliferation indexes (Figure 3). The expansion and replication indexes determine the foldexpansion of the whole population and of responding cells, respectively. A higher value in these parameters correlates with a higher quantity of cells after the proliferative process. The proliferation index is the number of divisions that cells from the original population have undergone divided by the number of divided cells. Thus, this parameter considers the number of 
(A)

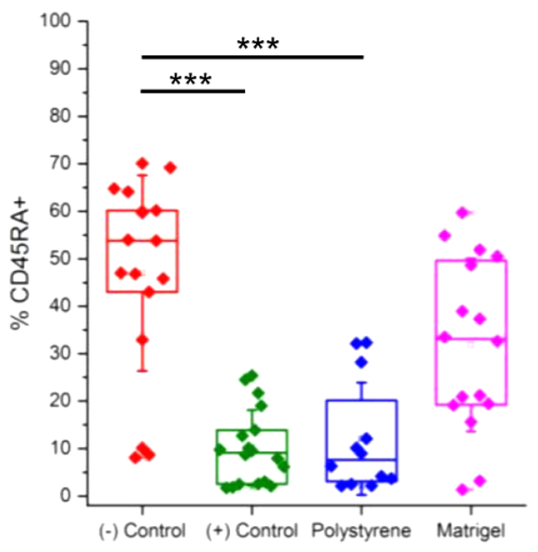

(D)

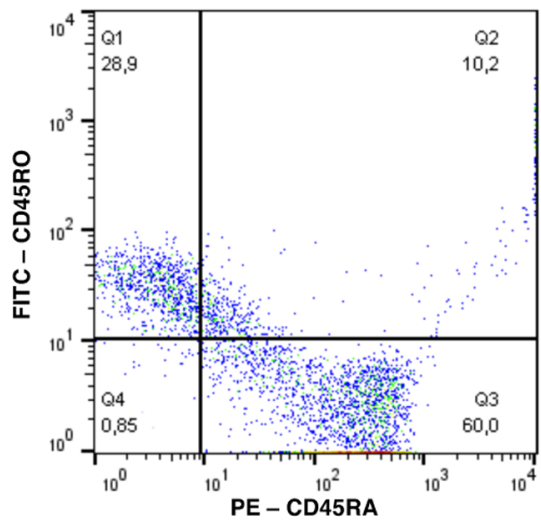

(B)

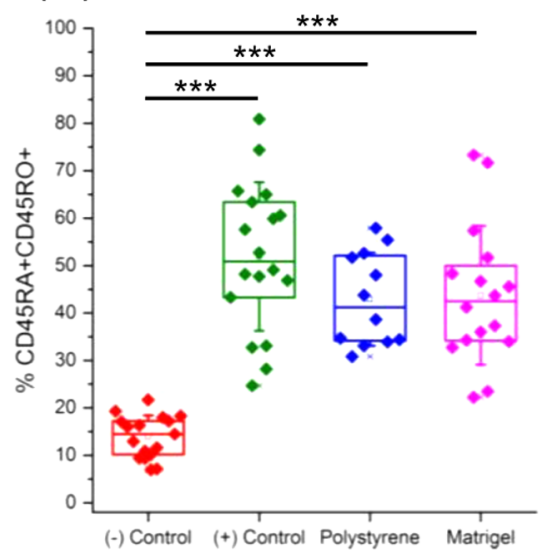

(E)

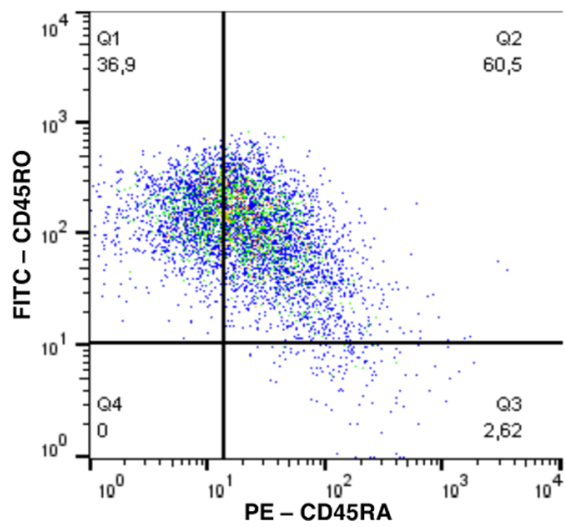

(C)

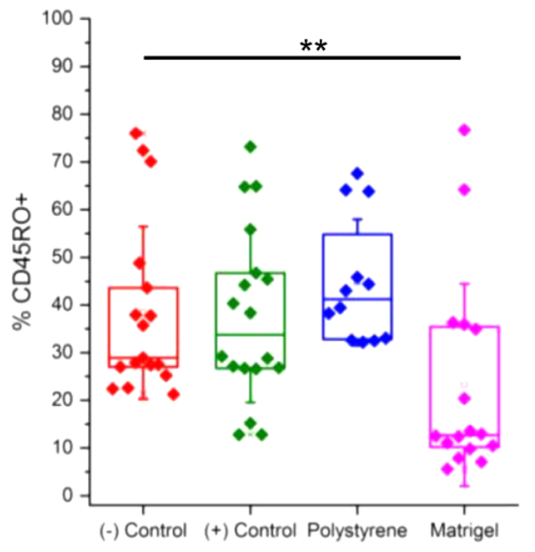

$(\mathrm{F})$

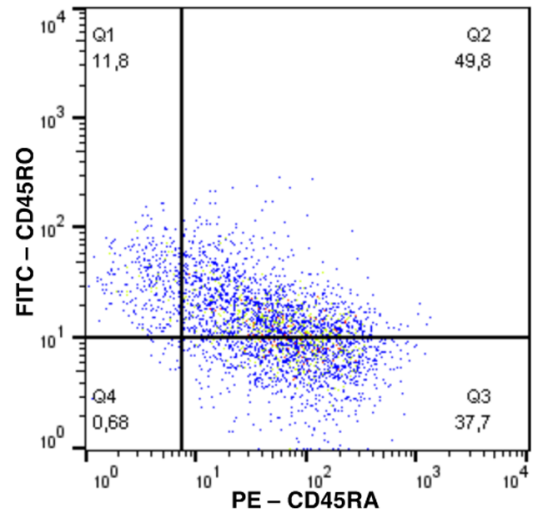

Figure 4. Percentage of (A) CD45RA ${ }^{+} \mathrm{T}$ cells, (B) $\mathrm{CD}_{4} 5^{+} \mathrm{T}$ cells, and (C) $\mathrm{CD} 45 \mathrm{RO}^{+} \mathrm{CD}^{+} \mathrm{T}$ cells in the different platforms. Representative dot plot graphs of cells in a (D) negative control, (E) 3D polystyrene scaffold and (F) Matrigel 5 days after the seeding. The results shown were obtained from $N_{\text {donors }}=6$, with a minimum of $N_{\text {donors } / \text { condition }}=4$. Statistical significance was determined by the Mann-Whitney $U$ test $(* * p<0.01, * * * p<$ $0.001)$.

responsive cells, i.e., a higher value correlates with a higher response to a proliferative stimulus. These three parameters are therefore relevant for cell therapy, showing how responsive the cells are to the proliferative stimulus, how much they divide after sensing this stimulus, and how many cells can finally be obtained. After 5 days of culture, Matrigel samples showed a median expansion index of 11.2, whereas the suspension exhibited an 8.9 and the 3D polystyrene scaffold an 11.1. In other words, for each million of cells seeded, Matrigel samples reached 11.2 million cells, the 3D polystyrene scaffold achieved 11.1 million cells, whereas in suspension, 8.9 million cells were obtained.

Although the median value of the $3 \mathrm{D}$ polystyrene scaffold is similar to Matrigel, it does not show significant differences in comparison with the positive control, as it does Matrigel. The replication index, which measures culture expansion of the responding cells, was of 19.1 for Matrigel, 12.6 for the positive control and 15.1 for the 3D polystyrene scaffold. These results indicate that the response of activated $\mathrm{T}$ cells was more effective in Matrigel samples than in the 3D polystyrene scaffold and the positive control. Similarly, Matrigel showed a median proliferation index value of 3.1 compared to the 2.6 and the 2.9 of suspension cells and the 3D polystyrene scaffold, respectively. Thus, the total number of divisions performed by the responding cells was significantly higher in Matrigel than in suspension. Additionally, the 3D polystyrene scaffold exhibited the same tendency, although for this system, the difference was not statistically different until day 6 , when the median value of the expansion index rose from 14.2 of the positive control to 22.1, the replication index median increased from 19.8 to 29.8, and the proliferation index ascended from 3.1 to 3.4. These results show the efficacy of these $3 \mathrm{D}$ environments given by the scaffolds in increasing proliferation compared to the standard culture in suspension and therefore suggest that the lack of IL-2 measured through ELISA was not due to an inefficient activation, but rather due to adhesion of IL-2 in the 3D matrices.

To determine the phenotype of the $\mathrm{CD}^{+} \mathrm{T}$ cells after proliferation, differentiation assays were performed 5 days after seeding (Figures 4 and S1). Two cell receptors were separately stained, CD45RA and CD45RO, given that following mitogenic stimulation, naive $\mathrm{T}$ cells gradually lose CD45RA and gain the CD45RO isoform, which is a marker of T cell memory. ${ }^{38}$ The percentage of $\mathrm{T}$ cells that express CD45RA and CD45RO prior to stimulation (negative control) is submitted to the intrinsic donor variability. Specifically, they showed a low percentage of the double positive population with a median value of $14.3 \%$, whereas the percentage of CD45RA ${ }^{+}$ranged from 26.5 to 67.8 (percentiles Q-25 and Q-75) with a median of 53.6\%, similar to 
$\mathrm{CD} 45 \mathrm{RO}^{+}$cells, which varied from 20.3 to $56.2 \%$, but in this case, exhibited a median value of $28.6 \%$.

After stimulation, the median value of $\mathrm{CD}_{45 \mathrm{RA}}^{+}$cells decreased to 8.9 and $7.5 \%$ in suspension and when using the $3 \mathrm{D}$ polystyrene scaffold, respectively, indicating that $\mathrm{CD} 4^{+} \mathrm{T}$ cells successfully differentiated into phenotypes other than naive. A further lower decrease was observed for cells activated in Matrigel, which showed a percentage of $\mathrm{CD}_{45 \mathrm{RA}}{ }^{+}$cells of $33 \%$. On the other hand, the percentage of double positive populations increased from the $14.3 \%$ of the negative control to $50.8 \%$ in the positive control, $41.2 \%$ in the $3 \mathrm{D}$ polystyrene scaffold, and $42.2 \%$ in Matrigel. Thus, the percentage of $\mathrm{T}$ cells showing both markers is significantly higher for all conditions compared to the negative control. The $\mathrm{CD} 45 \mathrm{RO}^{+}$population remained constant with median values of 33.7 and $41.7 \%$ in the positive control and the $3 \mathrm{D}$ polystyrene scaffold, respectively, whereas it was reduced to $12.5 \%$ in Matrigel. The differences observed in the latter could be attributed to its chemical stimulation, ${ }^{39}$ absent in the other two platforms, which may promote the conservation of the CD45RA phenotype. Nevertheless, this finding could also be explained by variations of the $\mathrm{T}$ cell stimulation given by the specific $3 \mathrm{D}$ structure and mechanical properties of Matrigel. Finally, representative dot plots of the negative control (Figure 4D), 3D polystyrene scaffold (Figure 4E), which is similar to the one obtained with the positive control (Figure S1), and Matrigel (Figure 4F) are shown. In the case of the 3D polystyrene scaffold and the positive control, the memory marker CD45RO appeared, increasing the double positive population, and drastically reducing the CD45RA phenotype. Nevertheless, cells expressed higher percentages of the CD45RA marker in Matrigel, thus probably conserving the higher capacity to proliferate of naive cells.

\section{CONCLUSIONS}

The 3D polystyrene scaffold significantly improved the proliferation rates, suggesting a clear benefit for substituting standard 2D culture systems by novel 3D platforms. Moreover, Matrigel, which has a truly 3D structure and additionally introduces a chemical input, showed promising results with significantly higher proliferation rates than the positive control with interesting phenotypes. However, Matrigel suffers from a high variability, which can be explained by its natural origin and the associated batch-to-batch variability. Thus, there is an underexplored area of investigation to be pursued consisting of designing 3D platforms specific for $\mathrm{T}$ cell culture to improve the current $\mathrm{T}$ cell expansion systems to introduce new in vitro models and facilitate the broad use of ACT in the clinics.

\section{EXPERIMENTAL SECTION}

4.1. Materials. Matrigel basement membrane matrix was acquired from Corning and 3D polystyrene scaffold from 3D Biotek. The $\mathrm{CD}^{+} \mathrm{T}$ cell isolation kit was purchased from Miltenyi Biotec S. L. (Germany), and the human IL-2 Quantikine ELISA kit was obtained from R\&D. Fetal bovine serum (FBS), penicillin/streptomycin (P/S), CellTrace CFSE cell proliferation kit, and the positive control Dynabeads were provided by Thermo Fisher Scientific. The antihuman antibodies CD3 FITC, CD4 PE, CD69 PE, CD45RA PE, CD45RO FITC, and their controls used for flow cytometry were acquired from Immunotools $\mathrm{GmbH}$ (Germany). The rest of the products were obtained from Sigma-Aldrich.
4.2. Instrumentation. Optical microscopy was performed in a Nikon Eclipse TE2000-E (Nikon, Japan). A BD FACSCanto flow cytometer (BD Biosciences) was used for flow cytometry analysis.

4.3. Software. The flow cytometry data were analyzed using the software FlowJo (FlowJo LLC), the microscope images were treated with FiJi (ImageJ), and the graphs (the boxes correspond to the interquartile ranges defined by the 25 th and 75th percentiles, the central line is the median, the whiskers show 1 standard deviation, $\times$ defines 1 st and 99th percentiles, - represents the maximum and minimum, and $\square$ is the average) and statistical tests were performed in Origin (OriginLab Corporation).

4.4. $\mathrm{CD}^{+} \mathrm{T}$ Cell Purification. Primary human $\mathrm{CD}^{+} \mathrm{T}$ cells were obtained through a purification process of buffy coats of healthy adult donors obtained from "Banc de Sang i Teixits" (Barcelona, Spain) after the approval of the "Ethics Committee on Animal and Human Experimentation" of the Autonomous University of Barcelona (No. 3511). Briefly, peripheral blood mononuclear cells were separated by density gradient centrifugation using Ficoll and $\mathrm{CD}^{+} \mathrm{T}$ cells were further purified using a $\mathrm{CD}^{+} \mathrm{T}$ cell isolation kit following the instructions of the manufacturer. To determine their purity, cell suspensions were prepared in phosphate-buffered saline (PBS) $+0.1 \%$ FBS and stained with antihuman CD3 FITC, antihuman $\mathrm{CD} 4 \mathrm{PE}$, and the negative controls for $30 \mathrm{~min}$ at $0{ }^{\circ} \mathrm{C}$. After washing, cells were analyzed by flow cytometry. Only samples that were at least $90 \%$ positive for both $\mathrm{CD}^{+}$ and $\mathrm{CD}^{+}$by flow cytometry (usually $\mathrm{CD} 3^{+} \mathrm{CD} 4^{+} \mathrm{T}$ cells > $95 \%$ ) were used for experiments. Viability was constantly above $80 \%$ (usually viability $>90 \%$ ).

4.5. Cell Culture and Seeding. $\mathrm{CD}^{+} \mathrm{T}$ cells were seeded on 96-well plates 1 day after purification in Roswell Park Memorial Institute (RPMI) medium with $10 \%$ FBS and 1\% P/ S. Cells were seeded at a concentration of $10^{6}$ cells $/ \mathrm{mL}$ and supplied with Dynabeads in a 1:1 ratio, as suggested by the manufacturer. For Matrigel, cells were seeded with Dynabeads on top of a previously formed hydrogel, following the manufacturer instructions, given their capacity to penetrate and migrate through it upon activation, as previously shown. ${ }^{23,24}$ For the 3D polystyrene scaffold, a $15 \mu \mathrm{L}$ drop of a concentrated cell suspension was seeded on top of the scaffold. After $3 \mathrm{~h}$ at $37{ }^{\circ} \mathrm{C}$, the medium was added. Positive controls were done by seeding the cells in suspension, as well as negative controls, which did not include Dynabeads.

4.6. $\mathrm{CD}^{+} \mathrm{T}$ Cell Activation. Cultures were evaluated 1 day after seeding by measuring secreted IL-2. The supernatant of the cell cultures was recovered and the IL- 2 concentration was determined by ELISA following the instructions of the manufacturer. Additionally, activation was also qualitatively assessed through cell morphology using optical microscopy.

4.7. $\mathrm{CD}^{+}{ }^{+}$T Cell Differentiation. Cultures were tested 56 days after seeding by flow cytometry. Cell suspensions were prepared in PBS $+0.1 \%$ FBS and stained with antihuman CD45RA PE, antihuman CD45RO FITC, and the corresponding negative controls for $30 \mathrm{~min}$ at $0{ }^{\circ} \mathrm{C}$. Afterward, they were washed and analyzed by flow cytometry.

4.8. $\mathrm{CD}^{+} \mathrm{T}$ Cell Proliferation. $\mathrm{CD} 4^{+} \mathrm{T}$ cells were stained before seeding with a CFSE cell proliferation kit. Briefly, a $1 \mu \mathrm{L}$ of CFSE stock solution was diluted in $99 \mu \mathrm{L}$ of PBS $+5 \%$ FBS. Cells were diluted in PBS up to a final volume of $900 \mu \mathrm{L}$ and put in contact with $100 \mu \mathrm{L}$ of the diluted CFSE solution through rapid agitation and incubated for $5 \mathrm{~min}$ at room 
temperature in the dark. After the incubation, $10 \mathrm{~mL}$ of ice cold PBS $+5 \%$ FBS were added to quench the staining. Then, the medium was extracted and cells were resuspended in RPMI + $10 \%$ FBS to achieve a concentration of $10^{6}$ stained cells $/ \mathrm{mL}$. 5-6 days after seeding, cells were tested by flow cytometry. The results obtained on day 5 (Figure $3 \mathrm{~A}-\mathrm{C}$ ) were performed with the same set of donors, whereas a different one was employed for the experiments of day 6 (Figure 3D-F).

\section{ASSOCIATED CONTENT}

\section{S Supporting Information}

The Supporting Information is available free of charge on the ACS Publications website at DOI: 10.1021/acsomega.8b00521.

Representative dot plot graph of $\mathrm{CD}^{+} \mathrm{T}$ cells in suspension (positive control) (PDF)

\section{AUTHOR INFORMATION}

\section{Corresponding Authors}

*E-mail: iratera@icmab.es (I.R.).

*E-mail: jguasch@icmab.es (J.G.).

ORCID $\odot$

Jaume Veciana: 0000-0003-1023-9923

Imma Ratera: 0000-0002-1464-9789

Judith Guasch: 0000-0002-3571-4711

Notes

The authors declare no competing financial interest.

\section{ACKNOWLEDGMENTS}

We acknowledge D. P. Rosenblatt for proofreading this article. The work was supported by the Spanish Ministry of Economy and Competitiveness MINECO (CTQ2013-40480-R and MAT2016-80826-R), the Networking Research Center on Bioengineering, Biomaterials, and Nanomedicine (CIBERBBN), and GenCat (2017-SGR 918). This research was also supported by the People program (Marie Curie Actions) of the 7th Framework Program of the European Union (FP7/20072013) through the grant agreement No. 600388 of REA with the Agency for Business Competitiveness ACCIÓ through a Tecniospring fellowship (TECSPR15-1-0015). The work was also funded by the Max Planck Society through the Max Planck Partner Group "Dynamic Biomimetics for Cancer Immunotherapy" in collaboration with the Max Planck Institute for Medical Research. ICMAB-CSIC acknowledges support from the MINECO through the Severo Ochoa Program for Centers of Excellence in R\&D (SEV-2015-0496).

\section{REFERENCES}

(1) Murphy, K.; Weaver, C. Janeway's Immunology, 9rd ed.; Garland Science: Taylor \& Francis Group, LLC: New York, 2017.

(2) Hanahan, D.; Weinberg, R. A. Hallmarks of cancer: The next generation. Cell 2011, 144, 646-674.

(3) Fesnak, A. D.; June, C. H.; Levine, B. L. Engineered T cells: The promise and challenges of cancer immunotherapy. Nat. Rev. Cancer 2016, 16, 566-581.

(4) Li, Y.; Xiao, Y.; Liu, C. The horizon of materiobiology: A perspective on material-guided cell behaviors and tissue engineering. Chem. Rev. 2017, 117, 4376-4421.

(5) Guasch, J.; Diemer, J.; Riahinezhad, H.; Neubauer, S.; Kessler, H.; Spatz, J. P. Synthesis of binary nanopatterns on hydrogels for initiating cellular responses. Chem. Mater. 2016, 28, 1806-1815.

(6) Guasch, J.; Conings, B.; Neubauer, S.; Rechenmacher, F.; Ende, K.; Rolli, C. G.; Kappel, C.; Schaufler, V.; Micoulet, A.; Kessler, H.; Boyen, H.-G.; Cavalcanti-Adam, E. A.; Spatz, J. P. Segregation versus colocalization: Orthogonally functionalized binary micropatterned substrates regulate the molecular distribution in focal adhesions. Adv. Mater. 2015, 27, 3737-3747.

(7) Rahmouni, S.; Lindner, A.; Rechenmacher, F.; Neubauer, S.; Sobahi, T. R. A.; Kessler, H.; Cavalcanti-Adam, E. A.; Spatz, J. P. Hydrogel micropillars with integrin selective peptidomimetic functionalized nanopatterned tops: A new tool for the measurement of cell traction forces transmitted through $\alpha \mathrm{v} \beta 3$ - or $\alpha 5 \beta 1$-integrins. Adv. Mater. 2013, 25, 5869-5874.

(8) Tatkiewicz, W. I.; Seras-Franzoso, J.; García-Fruitós, E.; Vazquez, E.; Ventosa, N.; Peebo, K.; Ratera, I.; Villaverde, A.; Veciana, J. Twodimensional microscale engineering of protein-based nanoparticles for cell guidance. ACS Nano 2013, 7, 4774-4784.

(9) Knight, E.; Przyborski, S. Advances in 3D cell culture technologies enabling tissue-like structures to be created in vitro. $J$. Anat. 2015, 227, 746-756.

(10) Geiger, B.; Spatz, J. P.; Bershadsky, A. D. Environmental sensing through focal adhesions. Nat. Rev. Mol. Cell Biol. 2009, 10, 21-33.

(11) Guasch, J.; Muth, C. A.; Diemer, J.; Riahinezhad, H.; Spatz, J. P. Integrin-assisted $\mathrm{T}$-cell activation on nanostructured hydrogels. Nano Lett. 2017, 17, 6110-6116.

(12) Matic, J.; Deeg, J.; Scheffold, A.; Goldstein, I.; Spatz, J. P. Fine tuning and efficient $\mathrm{T}$ cell activation with stimulatory $\mathrm{aCD} 3$ nanoarrays. Nano Lett. 2013, 13, 5090-5097.

(13) Deeg, J.; Axmann, M.; Matic, J.; Liapis, A.; Depoil, D.; Afrose, J.; Curado, S.; Dustin, M. L.; Spatz, J. P. T cell activation is determined by the number of presented antigens. Nano Lett. 2013, 13, 5619-5626.

(14) Cupedo, T.; Stroock, A.; Coles, M. Application of tissue engineering to the immune system: Development of artificial lymph nodes. Front. Immunol. 2012, 3, No. 343.

(15) Kleinman, H. K.; Martin, G. R. Matrigel: Basement membrane matrix with biological activity. Semin. Cancer Biol. 2005, 15, 378-386.

(16) Benton, G.; Arnaoutova, I.; George, J.; Kleinman, H. K.; Koblinski, J. Matrigel: From discovery and ECM mimicry to assays and models for cancer research. Adv. Drug Delivery Rev. 2014, 79-80, 318.

(17) Soofi, S. S.; Last, J. A.; Liliensiek, S. J.; Nealey, P. F.; Murphy, C. $\mathrm{J}$. The elastic modulus of matrigel as determined by atomic force microscopy. J. Struct. Biol. 2009, 167, 216-219.

(18) Giménez, A.; Uriarte, J. J.; Vieyra, J.; Navajas, D.; Alcaraz, J. Elastic properties of hydrogels and decellularized tissue sections used in mechanobiology studies probed by atomic force microscopy. Microsc. Res. Tech. 2017, 80, 85-96.

(19) Hwang, J. W.; Noh, S. M.; Kim, B.; Jung, H. W. Gelation and crosslinking characteristics of photopolymerized poly(ethylene glycol) hydrogels. J. Appl. Polym. Sci. 2015, 132, No. 41939.

(20) Kirshner, J.; Chen, C.-J.; Liu, P.; Huang, J.; Shively, J. E. CEACAM1-4S, a cell-cell adhesion molecule, mediates apoptosis and reverts mammary carcinoma cells to a normal morphogenic phenotype in a 3D culture. Proc. Natl. Acad. Sci. U.S.A. 2003, 100, 521-526.

(21) Fischbach, C.; Chen, R.; Matsumoto, T.; Schmelzle, T.; Brugge, J. S.; Polverini, P. J.; Mooney, D. J. Engineering tumors with 3D scaffolds. Nat. Methods 2007, 4, 855-860.

(22) Zaman, M. H.; Trapani, L. M.; Sieminski, A. L.; MacKellar, D.; Gong, H.; Kamm, R. D.; Wells, A.; Lauffenburger, D. A.; Matsudaira, P. Migration of tumor cells in $3 \mathrm{D}$ matrices is governed by matrix stiffness along with cell-matrix adhesion and proteolysis. Proc. Natl. Acad. Sci. U.S.A. 2006, 103, 10889-10894.

(23) Leppert, D.; Waubant, E.; Galardy, R.; Bunnett, N. W.; Hauser, $\mathrm{S}$. $\mathrm{L}$. T cell gelatinases mediate basement membrane transmigration in vitro. J. Immunol. 1995, 154, 4379-4389.

(24) Xia, M.; Leppert, D.; Hauser, S. L.; Sreedharan, S. P.; Nelson, P. J.; Krensky, A. M.; Goetzl, E. J. Stimulus specificity of matrix metalloproteinase dependence of human $\mathrm{T}$ cell migration through a model basement membrane. J. Immunol. 1996, 156, 160-167.

(25) Cameron, N. R.; Sherrington, D. C. Preparation and glass transition temperatures of elastomeric polyHIPE materials. J. Mater. Chem. 1997, 7, 2209-2212. 
(26) Sumarno; Sato, Y.; Takishima, S.; Masuoka, H. Production of polystyrene microcellular foam plastics and a comparison of late- and quick-heating. J. Appl. Polym. Sci. 2000, 77, 2383-2395.

(27) Gutsche, A. T.; Lo, H.; Zurlo, J.; Yager, J.; Leong, K. W. Engineering of a sugar-derivatized porous network for hepatocyte culture. Biomaterials 1996, 17, 387-393.

(28) Baker, S. C.; Atkin, N.; Gunning, P. A.; Granville, N.; Wilson, K.; Wilson, D.; Southgate, J. Characterisation of electrospun polystyrene scaffolds for three-dimensional in vitro biological studies. Biomaterials 2006, 27, 3136-3146.

(29) Fedorovich, N. E.; Alblas, J.; Hennink, W. E.; Öner, F. C.; Dhert, W. J. A. Organ printing: The future of bone regeneration? Trends Biotechnol. 2011, 29, 601-606.

(30) Caicedo-Carvajal, C. E.; Liu, Q.; Remache, Y.; Goy, A.; Suh, K. $S$. Cancer tissue engineering: A novel $3 \mathrm{D}$ polystyrene scaffold for in vitro isolation and amplification of lymphoma cancer cells from heterogeneous cell mixtures. J. Tissue Eng. 2011, 2011, No. 362326.

(31) Mahnke, Y. D.; Brodie, T. M.; Sallusto, F.; Roederer, M.; Lugli, E. The who's who of T-cell differentiation: Human memory T-cell subsets. Eur. J. Immunol. 2013, 43, 2797-2809.

(32) Tomei, A. A.; Siegert, S.; Britschgi, M. R.; Luther, S. A.; Swartz, M. A. Fluid flow regulates stromal cell organization and CCL21 expression in a tissue-engineered lymph node microenvironment. J. Immunol. 2009, 183, 4273-4283.

(33) Lefort, C. T.; Kim, M. Human T lymphocyte isolation, culture and analysis of migration in vitro. J. Visualized Exp. 2010, 40, No. e2017.

(34) Lämmermann, T.; Germain, R. N. The multiple faces of leukocyte interstitial migration. Semin. Immunopathol. 2014, 36, 227251.

(35) Lepzelter, D.; Bates, O.; Zaman, M. Integrin clustering in two and three dimensions. Langmuir 2012, 28, 5379-5386.

(36) Ribeiro, A.; Balasubmramanian, S.; Hughes, D.; Vargo, S.; Powell, E. M.; Leach, J. B. $\beta 1$-integrin cytoskeletal signaling regulates sensory neuron response to matrix dimensionality. Neuroscience 2013, $248,67-78$.

(37) Sung, K. E.; Su, X.; Berthier, E.; Pehlke, C.; Friedl, A.; Beebe, D. J. Understanding the impact of $2 \mathrm{D}$ and $3 \mathrm{D}$ fibroblast cultures on in vitro breast cancer models. PLoS One 2013, 8, No. e76373.

(38) Bujan, W.; Schandene, L.; Ferster, A.; Valck, C. D.; Goldman, M.; Sariban, E. Abnormal T-cell phenotype in familial erythrophagocytic lymphohistiocytosis. Lancet 1993, 342, 1296-1298.

(39) Griffith, L. G.; Swartz, M. A. Capturing complex 3D tissue physiology in vitro. Nat. Rev. Mol. Cell Biol. 2006, 7, 211-224. 